\title{
PERENCANAAN BAHAN BAKU DAN HASIL PRODUKSI MENGGUNAKAN METODE LINIER PROGRAMMING SIMPLEK
}

\author{
Monika Handayani \\ Jurusan Akuntansi Politeknik Negeri Banjarmasin \\ monika_handayani@akuntansipoliban.ac.id \\ Eka Kusuma Dewi \\ Jurusan Akuntansi Politeknik Negeri Banjarmasin \\ Eka kusumadewi@akuntansipoliban.ac.id
}

\begin{abstract}
$C V$. Baja Utama Landasan Ulin is a business entity that manufactures various products using the basic ingredients of iron. In the management of raw materials for the production of common regulatory process raw materials into sections for further processing. This setting is often done manually without doing careful planning, so that at the end of each production process there are many remaining pieces of the raw materials that should be used in production. In addition to the determination of the production is necessary to reference how the product should be made for each type of existing products. This is often an important factor that pushed for the optimization of production planning in determining the number of products for each type of product and raw material consumption.Linear Programming is one of the methods used in production planning to regulate the use of raw materials is limited. Simplex method is part of the linear programming method that can be used in the production planning system implementation. Simplex method identifies an initial basic solution and then move systematically to other basic solution that has the potential to improve the value of the objective function. The calculation result of production planning using the simplex method can be used as a reference in the decision making production planning. By building an application using the simplex method can assist in the calculation of production peencanaan more efficiently and effectively. Accuracy testing system constructed show significant results with great value reached $94 \%$ level of accuracy.

Keywords: simplex, production planning, the maximum gain, linear programming
\end{abstract}

\section{ABSTRAK}

CV. Baja Utama Landasan Ulin Kalimantan Selatan merupakan badan usaha yang memproduksi bermacam-macam produk yang memakai bahan dasar dari besi. proses pengaturan bahan baku menjadi beberapa bagian untuk diproses lebih lanjut. Pengaturan ini sering dilakukan secara manual tanpa melakukan perencanaan yang matang, sehingga pada setiap akhir proses produksi banyak terdapat sisa potongan bahan baku yang seharusnya dapat dimanfaatkan dalam produksi. Dalam pengaturan perencanaan produksi pada permasalahan di atas, diperlukan sebuah metode yang dapat menjawab permasalahan tersebut. Linear Programming merupakan salah satu metode yang dipakai dalam perencanaan produksi dengan mengatur pemakaian bahan baku yang bersifat terbatas. Metode Simpleks adalah bagian dari metode LP yang dapat dipakai dalam implementasi sistem perencanaan produksi tersebut. bahwa tingkat kualitas dari akurasi yang dihasilkan system sudah sesuai dengan yang diharapkan dengan tingkat akurasi mencapai 94\%

Kata Kunci simplex, perencanaan produksi, keuntungan maksimum, program linear

\section{PENDAHULUAN}

CV. Baja Utama Landasan Ulin

Kalimantan Selatan merupakan badan usaha yang memproduksi bermacammacam produk yang memakai bahan dasar dari besi. Beberapa produk yang dihasilkan berupa pagar besi, canopy, peralatan permainan anak dan teralis. Dalam pengaturan produksinya, perlu dilakukan perencanaan berkaitan dengan penentuan hasil produk dan bahan baku yang tersedia. Dimana bahan baku yang diperlukan yaitu antara lain besi, fiber, carbonet dan cat.

Dalam pengelolaan bahan baku untuk produksi sering terjadi proses pengaturan bahan baku menjadi beberapa bagian untuk diproses lebih lanjut. Pengaturan ini sering dilakukan secara manual tanpa melakukan 
perencanaan yang matang, sehingga pada setiap akhir proses produksi banyak terdapat sisa potongan bahan baku yang seharusnya dapat dimanfaatkan dalam produksi. Hal ini sering menjadi faktor penting yang mendorong untuk dilakukan optimasi perencanaan produksi dalam penentuan jumlah produk untuk tiap jenis produk dan pemakaian bahan baku.

Dalam pengaturan perencanaan produksi pada permasalahan di atas, diperlukan sebuah metode yang dapat menjawab permasalahan tersebut. Linear Programming merupakan salah satu metode yang dipakai dalam perencanaan produksi dengan mengatur pemakaian bahan baku yang bersifat terbatas. Metode Simpleks adalah bagian dari metode LP yang dapat dipakai dalam implementasi sistem perencanaan produksi tersebut. Metode simpleks merupakan prosedur perhitungan yang berulang (iteratif) dimana setiap pengulangan (iterasi) berkaitan dengan satu pemecahan dasar.( Muhiddin Sirat, 2007).

Dalam sistem aplikasi ini nantinya akan dijelaskan bagaimana penentuan pemecahan dasar dalam metode simpleks umumnya melibatkan perincian perhitungan yang menjemukan sehingga menjadi lebih mudah dan berorientasi otomatisasi.

Tujuan penelitian ini adalah untuk merancang dan membangun sistem pengaturan pemakaian bahan baku produksi dan perencanaan hasil produksi berjenis besi menggunakan metode linier programming simpleks.

Manfaat penelitian ini adalah untuk :

1. Menghasilkan perhitungan perencanaan produksi yang sebagai alat ukur untuk pengambilan keputusan berbasis komputer untuk membantu dalam mencapai keuntungan yang maksimum.

2. Membantu pengusaha dalam mengambil keputusan tentang pengendalian produksi.

Agar suatu persoalan dapat dipecahkan dengan teknik Linear Programming harus memenuhi syarat berikut :

1. Harus dapat dirumuskan secara matematis, agar mudah dalam pembahasan dalam penggunaan metode Linear Programming khususnya dengan Model Metode Simpleks.

Contoh rumusan matematika untuk pembatasan dari persoalan Linear Programming :

Cari $x_{j}, j=1,2, \ldots, n$

s.r.s $: Z=\sum_{j=1}^{n} c_{j} x_{j}=$ maksimum

$d . p: \sum_{j=1}^{n} a_{i j} x_{j} \leq h_{i}, \quad i=1,2, \ldots, n$ $x_{j} \geq 0$

2. Harus jelas fungsi objektif (keuntungan) yang linear yang harus dibuat optimum. Adapun rumusan untuk menyatakan fungsi objektif yang menggambarkan nilai keuntungan yang akan menjadi 
sasaran perancangan produksi adalah sebagai berikut:

$Z=c_{1} x_{1}+c_{2} x_{2}+\ldots+c_{j} x_{j}+\ldots+c_{n} x_{n}:$ maksimum

3. Pembatasan-pembatasan harus dinyatakan dalam ketidaksamaan yang linear. Rumusan dari pembatasanpembatasan yang merupakan bagian dari perhitungan untuk mendapatkan kondisi optimum, dapat dinyatakan dalam pertidaksamaan seperti di bawah ini:

$a_{11} x_{1}+a_{12} x_{2}+\ldots \ldots+a_{i j} x_{j}+\ldots \ldots+a_{1 n} x_{n} \leq h_{1}$

$a_{21} x_{1}+a_{22} x_{2}+\ldots \ldots+a_{2 j} x_{j}+\ldots \ldots+a_{2 n} x_{n} \leq h_{2}$

......

$a_{i 1} x_{1}+a_{i 2} x_{2}+\ldots \ldots+a_{i j} x_{j}+\ldots \ldots+a_{i n} x_{n} \leq h_{i}$

.......

$a_{m i} x_{1}+a_{m 2} x_{2}+\ldots \ldots+a_{m j} x_{j}+\ldots \ldots+a_{m n} x_{n} \leq h_{m}$

Dimana $x_{j} \geq 0, \mathrm{j}=1,2, \ldots, \mathrm{n}$

Beberapa hal yang harus diperhatikan dalam merancang sistem dengan menggunakan metode Linear Programming untuk perencanaan produksi, yaitu:

1. Fungsi obyektif harus didefinisikan secara jelas dan dinyatakan sebagai fungsi obyektif yang linear. Misalnya jumlah hasil penjualan harus maksimum, jumlah biaya transpor harus minimum.

2. Harus ada alternatif pemecahan untuk dipilih salah satu yang terbaik.

3. Sumber-sumber dan aktivitas mempunyai sifat dapat ditambahkan (additivity).

4. Fungsi objektif dan ketidaksamaan untuk menunjukkan adanya pembatasan harus linear.
5. Variabel keputusan harus positif, tidak boleh negatif ( $x j \geq 0$, untuk semua $j)$.

6. Sumber-sumber dan aktivitas mempunyai sifat dapat dibagi (divisibility).

7. Sumber-sumber dan aktivitas mempunyai jumlah yang terbatas (finkiteness).

8. Aktivitas harus proporsional terdahap sumber-sumber. Hal ini berarti ada hubungan yang linear antara aktivitas dengan sumber-sumber. Misalnya output dinaikkan 2 kali, kalau demand naik 1,5 kali maka output harus naik 1,5 kali, jadi menggunakan prinsip constant return to scale.

9. Model programming deterministik, artinya sumber dan aktivitas diketahui secara pasti (single-valued expectations).

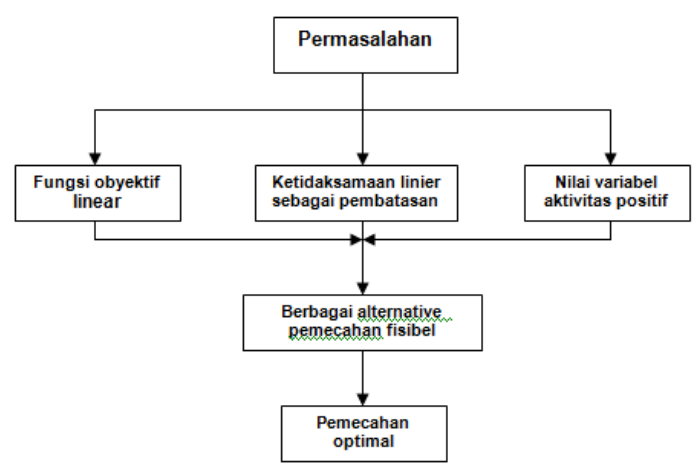

Gambar 1. Prosedur penerapan teknik Linear Programming Langkah-langkah penyelesaiannya adalah sebagai berikut :

1. Periksa apakah tabel layak atau tidak. Kelayakan tabel simpleks dilihat dari solusi (nilai kanan). Jika solusi ada yang bernilai negatif, maka tabel tidak layak. 
Tabel yang tidak layak tidak dapat diteruskan untuk dioptimalkan.

2. Tentukan kolom pivot. Penentuan kolom pivot dilihat dari koefisien fungsi tujuan (nilai di sebelah kanan baris z) dan tergantung dari bentuk tujuan. Jika tujuan maksimisasi, maka kolom pivot adalah kolom dengan koefisien paling negatif. Jika kolom pivot ditandai dan ditarik ke atas, maka kita akan mendapatkan variabel keluar. Jika nilai paling negatif lebih dari satu, pilih salah satu secara sembarang.

3. Tentukan baris pivot. Baris pivot ditentukan setelah membagi nilai solusi dengan nilai kolom pivot yang bersesuaian (nilai yang terletak dalam satu baris). Dalam hal ini, nilai negatif dan 0 pada kolom pivot tidak diperhatikan, artinya tidak ikut menjadi pembagi. Baris pivot adalah baris dengan rasio pembagian terkecil. Jika baris pivot ditandai dan ditarik ke kiri, maka kita akan mendapatkan variabl keluar. Jika rasio pembagian terkecil lebih dari satu, pilih salah sau secara sembarang.

4. Tentukan elemen pivot. Elemen pivot merupakan nilai yang terletak pada perpotongan kolom dan baris pivot.

5. Bentuk tabel simpleks baru. Tabel simpleks baru dibentuk dengan pertama sekali menghitung nilai baris pivot baru. Baris pivot baru adalah baris pivot lama dibagi dengan elemen pivot. Baris baru lainnya merupakan pengurangan nilai kolom pivot baris yang bersangkutan dikali baris pivot baru dalam satu kolom terhadap baris lamanya yang terletak pada kolom tersebut.

6. Periksa apakah tabel sudah optimal. Keoptimalan tabel dilihat dari koefisien fungsi tujuan (nilai pada baris Z) dan tergantung dari bentuk tujuan. Untuk tujuan maksimisasi, tabel sudah optimal jika semua nilai pada baris $\mathrm{z}$ sudah positif atau 0 .

\section{METODE PENELITIAN}

Kerangka pemikiran pada penelitian ini dapat digambarkan seperti pada gambar 1. di bawah ini. 
Setelah melakukan tahap perencanaan,

selanjutnya akan dilakukan proses

pembangunan sistem perencanaan produksi menggunakan metode simpleks. Beberapa tahap dalam melakukan analisis sistem yaitu :

1. Melakukan survey untuk melakukan analisa permasalahan pada obyek penelitian, sehingga dapat ditemukan akar permasalahan yang akan dicari penyelesaiannya.

2. Menganalisa permasalahan yang terjadi dengan melakukan studi literatur, sehingga ditemukan metode yang sesuai untuk pemecahan masalah tersebut.

3. Pengumpulan data, yaitu berupa beberapa nama produk dan bahan baku yang tersedia.

4. Analisa kebutuhan sistem

5. Merancang sistem perhitungan perencanaan jumlah produksi dengan menggunakan Metode Simpleks.

6. Melakukan perancangan sistem.

7. Mengimplementasikan sistem perhitungan perencanaan jumlah produksi dengan menggunakan Metode Simpleks.

8. Testing Program.

9. Penulisan Laporan

Lokasi penelitian di CV. Baja Utama Landasan Ulin dan Laboratorium Komputer Prodi Komputerisasi Akuntansi.

Bahan yang digunakan dalam penelitian ini yaitu Data-data berupa bahan baku, jenis produk, jumlah persediaan dan harga produk per unit.

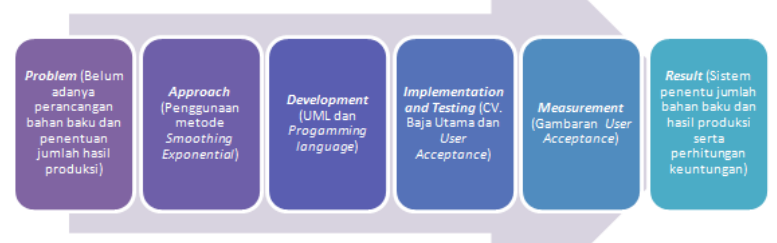

Gambar 2. Skema Kerangka Pemikiran Penelitian

Sampel data yang digunakan dalam penelitian ini adalah data proses produksi pada CV. Baja Utama Landasan Ulin.

Tabel 1. Kebutuhan Alternative

\begin{tabular}{|c|c|c|c|c|c|c|}
\hline \multirow[b]{2}{*}{ Jenis Bahan Baku } & \multicolumn{5}{|c|}{ Jumlah bahan setiap 1 Produk } & \multirow{2}{*}{$\begin{array}{c}\text { Bahan Baku } \\
\text { maksimum yang } \\
\text { tersedia }\end{array}$} \\
\hline & $\begin{array}{c}\text { Ayun } \\
\text { Jumboo }\end{array}$ & $\begin{array}{l}\text { Avyn } \\
\text { Single }\end{array}$ & $\begin{array}{c}\text { Ayun Extra } \\
\text { Jumbo }\end{array}$ & Ayun Cekly & $\begin{array}{c}\text { Jungitan } \\
\text { Single }\end{array}$ & \\
\hline Pipa Ulir 2ind & 5 & 5 & 1 & 3 & 1 & 30 Batang \\
\hline Plat Strip $1 \%$ inci & 50 & 1 & 51 & 1 & 1 & 140 Batang \\
\hline Plat Strip 1 ind & 1 & 40 & 1 & 1 & 1 & 96 Batang \\
\hline Pipa Polos 2 \%inci & 1 & 1 & 5 & 1 & 1 & 24 Batang \\
\hline Pipa Ulir 1 \% inci & 1 & 1 & 1 & 1 & 4 & 25 Batang \\
\hline Pipa Ulir 1 inci & 1 & 1 & 1 & 2 & 1 & 13 Batang \\
\hline Tinner & 1 & 1 & 1 & 1 & 1 & 8 Batang \\
\hline Cat & 1 & 1 & 1 & 1 & 5 & 7 Batang \\
\hline Pipa Polos 2 inci & 1 & 1 & 1 & 1 & 1 & 13 Batang \\
\hline Tukang & 20 & 18 & 25 & 1 & 1 & 10 orang \\
\hline Waktu & 40 & 32 & 40 & 40 & 32 & $56 \mathrm{Jam}$ \\
\hline
\end{tabular}

Teknik pengumpulan data yang digunakan pada penelitian ini adalah sebagai berikut:

Observasi

Pada metode ini dilakukan pengamatan pada bagian produksi untuk mengetahui perencanaan proses produksi dengan pemakaian bahan baku yang terbatas untuk mendapatkan jumlah produksi yang dapat menghasilkan keuntungan yang besar.

Interview atau Wawancara 
Metode ini digunakan untuk mendapatkan informasi yang lebih terperinci tentang teknik perencanaan produksi dan penentuan jumlah produksi yang dihasilkan.

3. Metode Kepustakaan

Metode ini dilakukan dengan membaca, mengamati dan memahami beberapa sumber tertulis yang didapatkan dari buku-buku maupun internet sehingga diperoleh informasi yang membantu proses analisa masalah, perancangan dan pembangunan sistem komputerisasi tentang perencanaan produksi berdasarkan bahan baku yang tersedia, sampai dengan penyusunan penelitian ini.

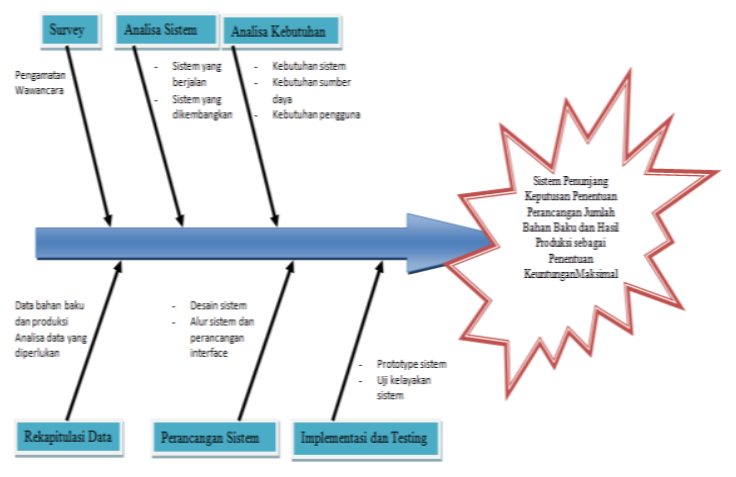

Gambar 3. Diagram Fishbon tahapan penelitian

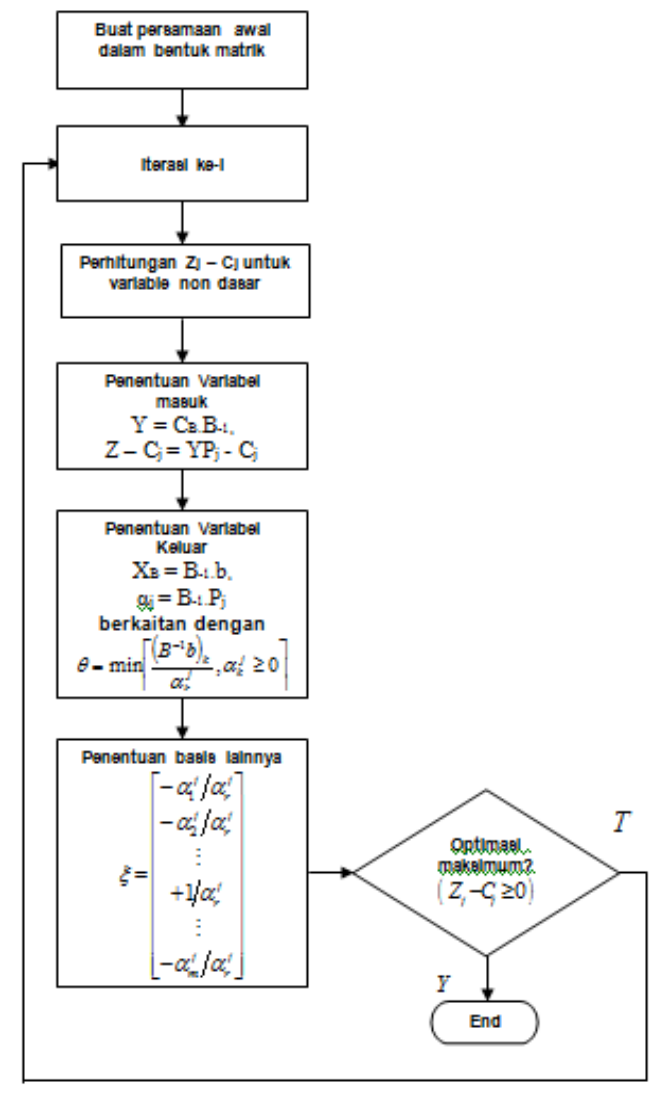

Gambar 4. Tahapan perhitungan metode simplek

\section{HASIL DAN PEMBAHASAN}

Penentuan solusi optimal menggunakan metode simpleks didasarkan pada teknik eleminasi Gauss Jordan. Penentuan solusi optimal dilakukan dengan memeriksa titik ekstrim satu per satu dengan cara perhitungan iteratif. Sehingga penentuan solusi optimal dengan simpleks dilakukan tahap demi tahap yang disebut dengan iterasi. Iterasi ke-i hanya tergantung dari iterasi sebelumnya (i-1).

Sebelum melakukan perhitungan iteratif untuk menentukan solusi optimal, pertama sekali bentuk umum pemrograman linier dirubah ke dalam bentuk baku 
terlebih dahulu. Bentuk baku dalam metode simpleks tidak hanya mengubah persamaan kendala ke dalam bentuk sama dengan, tetapi setiap fungsi kendala harus diwakili oleh satu variabel basis awal. Variabel basis awal menunjukkan status sumber daya pada kondisi sebelum ada aktivitas yang dilakukan. Dengan kata lain, variabel keputusan semuanya masih bernilai nol. Dengan demikian, meskipun fungsi kendala pada bentuk umum pemrograman linier sudah dalam bentuk persamaan, fungsi kendala tersebut masih harus tetap berubah.

Pada permasalahan yang terjadi untuk perencanaan produksi Ayunan, jungkitan dan bandulan, maka dapat dijabarkan seperti di bawah ini:

CV. Baja Utama Landasa Ulin memiliki usaha memproduksi ayunan, jungkitan dan bandulan. Untuk memproduksi lima jenis produk tersebut diperlukan bahan baku yang terdiri dari pipa ulir 2 inci, plat strip 1 inci, pipa ppolos 2,5 inci, pipa ulir 1 inci, besi siku $3 \times 3$, besi siku $4 \times 4$, pipa polos 2 inci, besi $12 \mathrm{ML}$ dan jam kerja. Dari beberapa bahan baku yang ada tersedia jumlah maksimum bahan baku, seperti terlihat pada tabel $1 \mathrm{di}$ atas. Masalah yang harus dipecahkan pada persoalan di atas adalah bagaimana menentukan jumlah unit setiap jenis produk yang akan diproduksi dalam setiap bulannya.

Penyelesaian :

Untuk menyelesaiankan permasalahan optimasi, maka ditentukan variabel yang tak diketahui (variabel keputusan) dan dinyatakan dalam symbol matematika.
1. Variabel Keputusan.

Dimana,

$$
\begin{aligned}
& \text { X1 = Ayun Jumbo } \\
& \text { X2 }=\text { Ayun Single } \\
& \text { X3 = Ayun ekstra jumbo } \\
& \text { X4 = Ayun Cekly } \\
& \text { X5 = Jungkitan Single }
\end{aligned}
$$

2. Berdasarkan pernyataan di atas, maka terbentuklah sebuah fungsi tujuan dan fungsi kendala :

Maksimumkan $Z=2750000 X 1+$

$2000000 \mathrm{X} 2+3250000 \mathrm{X} 3+2500000 \mathrm{X} 4+$ $25000000 \mathrm{X}_{5}$

Dimana :

$\mathrm{Z}=$ Keuntungan yang ingin dimaksimumkan

$\mathrm{Y}=$ Keuntungan persatuan produk $\mathrm{X}=$ Jenis mainan/variabel keputusan

Kendala $=5 \mathrm{X} 1+5 \mathrm{X} 2+\mathrm{X} 3+3 \mathrm{X} 4+\mathrm{X}_{5} \leq$ 30

$$
\begin{array}{r}
35 \mathrm{X} 1+25 \mathrm{X} 2+17 \mathrm{X} 3+\mathrm{X} 4+14 \mathrm{X}_{5} \leq 140 \\
\mathrm{X} 1+40 \mathrm{X} 2+\mathrm{X} 3+\mathrm{X} 4+\mathrm{X}_{5} \leq 96 \\
\mathrm{X} 1+\mathrm{X} 2+5 \mathrm{X} 3+\mathrm{X} 4+\mathrm{X}_{5} \leq 24 \\
\mathrm{X} 1+\mathrm{X} 2+\mathrm{X} 3+\mathrm{X} 4+4 \mathrm{X}_{5} \leq 25 \\
\mathrm{X} 1+\mathrm{X} 2+\mathrm{X} 3+2 \mathrm{X} 4+\mathrm{X}_{5} \leq 13 \\
\mathrm{X} 1+\mathrm{X} 2+\mathrm{X} 3+\mathrm{X} 4+\mathrm{X} 5 \leq 8 \\
\mathrm{X} 1+\mathrm{X} 2+\mathrm{X} 3+\mathrm{X} 4+2 \mathrm{X} \leq 7 \\
\mathrm{X} 1+\mathrm{X} 2+\mathrm{X} 3+\mathrm{X} 4+\mathrm{X}_{5} \leq 13 \\
2 \mathrm{X} 1+2 \mathrm{X} 2+3 \mathrm{X} 3+\mathrm{X} 4+\mathrm{X}_{5} \leq 10 \\
12 \mathrm{X}_{1}+27 \mathrm{X}_{2}+15 \mathrm{X}_{3}+8 \mathrm{X}_{4}+10 \mathrm{X}_{5} \leq 56 \\
\mathrm{X} 1, \mathrm{X} 2, \mathrm{X} 3, \mathrm{X} 4, \mathrm{X}_{5} \leq 0
\end{array}
$$

Langkah selanjutnya adalah merubah fungsi kendala dari pertidaksamaan menjadi persamaan dengan menambahkan variabel slack, sehingga menjadi persamaan seperti di bawah ini.

Fungsi tujuan : 
Z - 2750000X1 - 2000000X2 - 3250000X3

$-2500000 X 4-25000000 X_{5}+S_{1}+S_{2}+S_{3}$

$+\mathrm{S}_{4}+\mathrm{S}_{5}+\mathrm{S}_{6}+\mathrm{S}_{7}+\mathrm{S}_{8}+\mathrm{S}_{9}+\mathrm{S}_{10}+\mathrm{S}_{11}=0$

Fungsi kendala :

$5 \mathrm{X} 1+5 \mathrm{X} 2+\mathrm{X} 3+3 \mathrm{X} 4+\mathrm{X}_{5}+\mathrm{S}_{1}$

$35 \mathrm{X} 1+25 \mathrm{X} 2+17 \mathrm{X} 3+\mathrm{X} 4+14 \mathrm{X}_{5}+\mathrm{S}_{2}=$ 140

$$
\begin{array}{r}
\mathrm{X} 1+40 \mathrm{X} 2+\mathrm{X} 3+\mathrm{X} 4+\mathrm{X}_{5}+\mathrm{S}_{3}=96 \\
\mathrm{X} 1+\mathrm{X} 2+5 \mathrm{X} 3+\mathrm{X} 4+\mathrm{X}_{5}+\mathrm{S}_{4}=24 \\
\mathrm{X} 1+\mathrm{X} 2+\mathrm{X} 3+\mathrm{X} 4+4 \mathrm{X}_{5}+\mathrm{S}_{5}=25 \\
\mathrm{X} 1+\mathrm{X} 2+\mathrm{X} 3+2 \mathrm{X} 4+\mathrm{X}_{5}+\mathrm{S}_{6}=13 \\
\mathrm{X} 1+\mathrm{X} 2+\mathrm{X} 3+\mathrm{X} 4+\mathrm{X} 5+\mathrm{S}_{7}=8 \\
\mathrm{X} 1+\mathrm{X} 2+\mathrm{X} 3+\mathrm{X} 4+5 \mathrm{X}+\mathrm{S}_{8}=7 \\
\mathrm{X} 1+\mathrm{X} 2+\mathrm{X} 3+\mathrm{X} 4+\mathrm{X}_{5}+\mathrm{S}_{9}=13 \\
2 \mathrm{X} 1+2 \mathrm{X} 2+3 \mathrm{X} 3+\mathrm{X} 4+\mathrm{X}_{5}+\mathrm{S}_{10}=10 \\
12 \mathrm{X}_{1}+27 \mathrm{X}_{2}+15 \mathrm{X}_{3}+8 \mathrm{X}_{4}+10 \mathrm{X}_{5}+\mathrm{S}_{11}=56 \\
\mathrm{X} 1, \mathrm{X} 2, \mathrm{X} 3, \mathrm{X} 4, \mathrm{X} 5, \mathrm{~S}_{1}
\end{array}
$$

$\mathrm{S}_{2}, \mathrm{~S}_{3}, \mathrm{~S}_{4}, \mathrm{~S}_{5}, \mathrm{~S}_{6}, \mathrm{~S}_{7}, \mathrm{~S}_{8}, \mathrm{~S}_{9}, \mathrm{~S}_{10}, \mathrm{~S}_{11} \leq 0$

Langkah selanjutnya dihitung dengan menggunakan tabel simpleks.

Hasil perhitungan dengan menggunakan metode simpleks, diperoleh solusi optimal dan status sumber daya dalam bentuk bahan mentah.

Dari table optimal dapat dijabarkan:

Solusi optimal $X_{1}=0 \quad X_{2}=2,3, X_{3}=$ $3,8, X_{4}=2,6423, X_{5}=1,25$ dan $Z=R p$. 24438302, artinya untuk mendapatkan keuntungan maksimum sebesar Rp. 24438302, maka perusahaan sebaiknya menghasilkan produk 1 sebesar 0 unit, produk 2 sebesar 0,06 unit, produk 3 sebesar 3,8 unit, produk 4 sebesar 2,6423 unit dan produk 5 sebesar 1,25 unit.
Sumber daya pertama dilihat dari keberadaan variabel basis awal dari setiap fungsi kendala pada table optimal. Dalam kasus di atas, untuk fungsi kendala pertama periksa keberadaan $S_{1}$ pada variabel basis tabel optimal. Periksa keberadaan $\mathrm{S}_{2}$ pada variabel basis table optimal untuk fungsi kendala kedua. Periksa keberadaan $\mathrm{S}_{3}$ pada variabel basis tabel optimal untuk fungsi kendala ketiga, dan seterusnya samapai $\mathrm{S}_{11}$. $\mathrm{S}_{1}=25$. Sumber daya ini disebut berlebih (abundant)

$\mathrm{S}_{2}=0$ Sumber daya ini disebut habis

$\mathrm{S}_{3}=0$. Sumber daya ini disebut habis

$\mathrm{S}_{4}=25$ Sumber daya ini disebut berlebih (abundant)

$\mathrm{S}_{5}=16$ Sumber daya ini disebut berlebih (abundant)

$\mathrm{S}_{6}=27$. Sumber daya ini disebut berlebih (abundant)

$\mathrm{S}_{7}=0$. Sumber daya ini disebut habis

$\mathrm{S}_{8}=0$. Sumber daya ini disebut habis

$\mathrm{S}_{9}=5$. Sumber daya ini disebut berlebih (abundant)

$\mathrm{S}_{10}=0$. Sumber daya ini disebut habis $\mathrm{S}_{11}=0$. Sumber daya ini disebut habis

Dengan menggunakan aplikasi sistem perencanaan produksi dan bahan baku menggunakan metode simpleks, maka dapat dihitung proses iterasi secara cepat.

\section{Status sumber daya :}




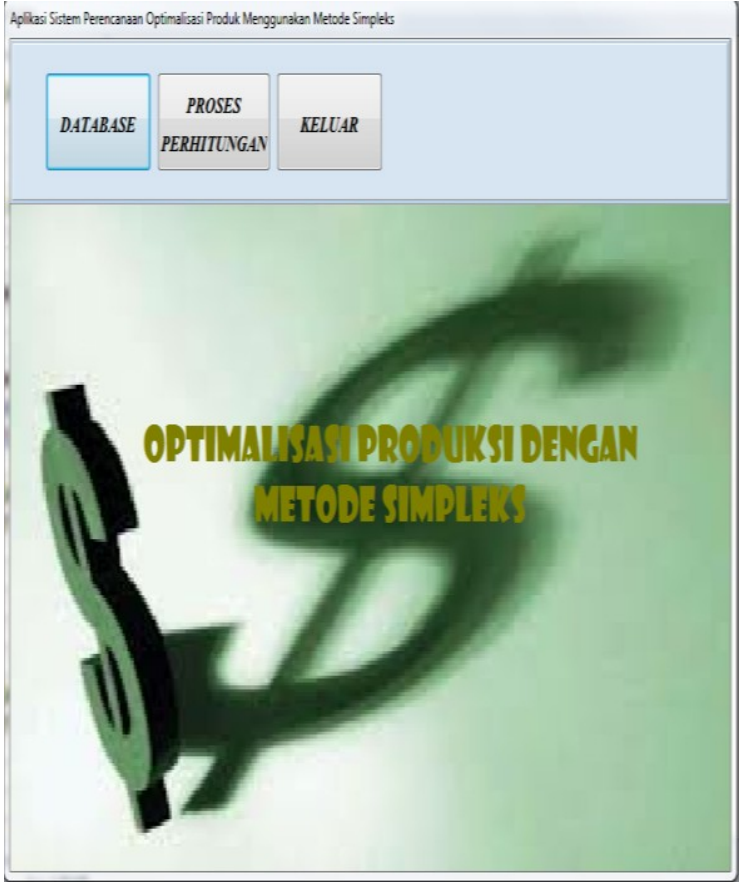

Gambar 5. Halaman Form Menu Utama

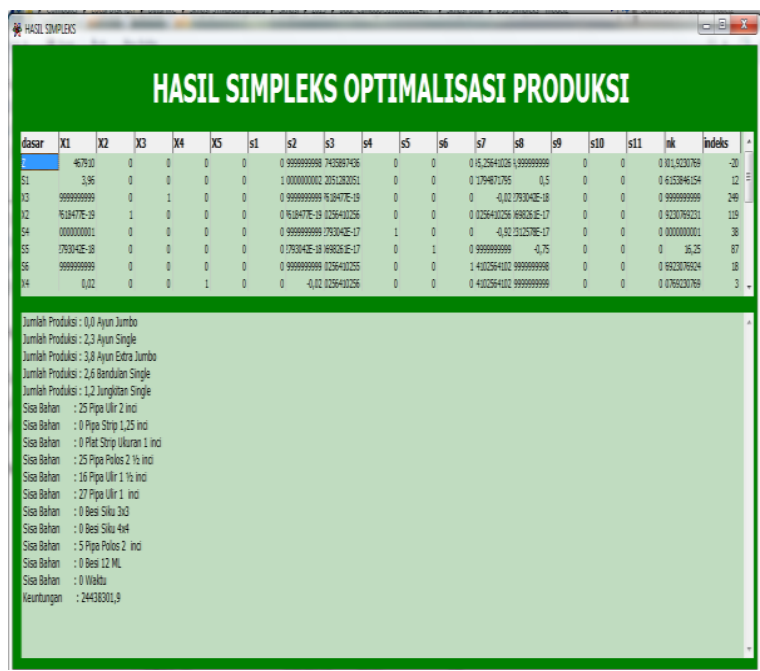

Gambar 6. Form Hasil Perhitungan Perencanaan Produksi

Laporan hasil perhitungan perencanaan produksi dan bahan baku menggunakan metode simpleks menghasilkan optimalisasi produksi, seperti pada gambar dibawah ini.

\begin{tabular}{|c|c|c|}
\hline \multicolumn{3}{|c|}{ LAPORAN OPTIMALISASI PRODUKSI } \\
\hline HASIL PRODUKSI & JUMLAH & PRODUKSI / BAHAN \\
\hline Jumlah Produksi & 0 & Ayun Jumbo \\
\hline Jumlah Produksi & 2 & Ayun Sngle \\
\hline Jumlah Produksi & 4 & Ayun Extra Jumbo \\
\hline Jumlah Produksi & 3 & Bandulan Sngle \\
\hline Jumlah Produksi & 1 & Jungktan Single \\
\hline Ssa Bahan & 25 & Ppa Uir 2 no \\
\hline Ssa Bahan & 0 & Ppa Strip 1,25 no \\
\hline Ssa Bahan & 0 & Plat Strip Ukuran 1 no \\
\hline Ssa Bahan & 25 & Ppa Polos 2 1/2 no \\
\hline Ssa Bahan & 16 & Ppa Uir 1 1/2 no \\
\hline Ssa Bahan & 27 & Pppa Ur 1 ino \\
\hline Ssa Bahan & 0 & Besi Sku $3 \times 3$ \\
\hline Ssa Bahan & 0 & Besi Sku $4 \times 4$ \\
\hline Ssa Bahan & 5 & Ppa Polos 2 nó \\
\hline Ssa Bahan & 0 & Besi $12 \mathrm{ML}$ \\
\hline Ssa Bahan & 0 & Waktu \\
\hline Besamya Keuntungan & 24438302 & Total Produksi \\
\hline
\end{tabular}

Gambar 5. Form laporan perhitungan optimalisasi produk

Pada hasil perhitungan menggunakan system seperti pada tampilan di atas, maka dari hasil perhitungan manual dan hasil perhitungan system dapat dibuat tabel pembandingan nilai hasil perhitungan sebagai pengukuran tingkat akurasi system dengan membandingkan hasil per variabel, seperti terlihat pada tabel di bawah ini. 
Tabel 2. Perbandingan Perhitungan Manual dan Sistem

\begin{tabular}{|c|c|c|c|c|}
\hline \multirow{2}{*}{ No. } & \multirow{2}{*}{ Variabel } & \multicolumn{2}{|c|}{ Hasil Nilai Perhitungan } & \multirow{2}{*}{$\begin{array}{c}\text { Keterangan } \\
\text { Akurasi }\end{array}$} \\
\hline & & Manual & Sistem & \\
\hline 1 & $z$ (obyektif) & 24438302 & 24438301,9 & Akurat \\
\hline 2 & Produk 1 (x1) & 0 & 0 & Akurat \\
\hline 3 & Produk 2 (x2) & 2,3 & 2 & Akurat \\
\hline 4 & Produk 3 (X3) & 4 & 3,8 & Akurat \\
\hline 5 & Produk $4(X 4)$ & 2,91666 & 3 & Akurat \\
\hline 6 & Produk 5(x5) & 1,25 & 1 & Akurat \\
\hline 7 & Slack (X1) & 25 & 25 & Akurat \\
\hline 8 & Slack (X2) & 0 & 0 & Akurat \\
\hline 9 & Slack (X3) & 0 & 0 & Akurat \\
\hline 10 & Slack $[\mathrm{x} 4 \mathrm{4}$ & 25 & 25 & Akurat \\
\hline 11 & Slack (X5) & 16 & 0 & Akurat \\
\hline 12 & Slack (X6) & 27 & 0 & Akurat \\
\hline 13 & Slack $(X 7)$ & 0 & 25 & Akurat \\
\hline 14 & Slack (XB) & 0 & 16 & Akurat \\
\hline 15 & Slack $(X 9)$ & 0 & 27 & Akurat \\
\hline 16 & Slack (x10) & 0 & 0 & Akurat \\
\hline 17 & Slack (X11) & 252 & 0 & Tidak Akurat \\
\hline
\end{tabular}

Sumber: Data primer

Sehingga jumlah data yang sesuai dengan kenyataan adalah 5 hasil perhitungan simpleks dan untuk mengetahui persentase tingkat akurasi rekomendasi yang dihasilkan digunakan rumus yaitu:

Akurasi $=($ Total uji yang sesuai $/$ Total item ui coba)x $100 \%$

Akurasi $=(16 / 17) \times 100 \%$

Akurasi $=94 \%$

Dari tingkat kesesuaian yang dihasilkan dapat dikatakan bahwa tingkat kualitas dari akurasi yang dihasilkan system sudah sesuai dengan yang diharapkan. Dan tingkat akurasi ini dapat ditampilkan dalam grafik diagram seperti di bawah

ini.
Grafik Prosentase Tingkat Akurasi Sistem Menggunakan Metode Simpleks

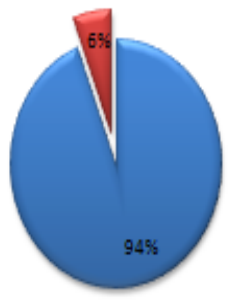

unkurat

widak Akurat

Gambar 8. grafik prosentase tingkat akurasi sistem menggunakan metode simpleks

\section{SIMPULAN DAN SARAN}

Aplikasi system perencanaan produksi permainan anak-anak menggunakan metode simpleks, menghasilkan tingkat akurasi sistem sebesar 94\%. Hal ini ditunjukkan dari proses pembandingan perhitungan perencanaan produk menggunakan metode simpleks dengan cara manual dan dengan cara memakai aplikasi yang dibangun.

Aplikasi perhitungan perencanaan optimalisasi produk permainan anak-anak ini dapat dirasa lebih efektif dalam melakukan proses perhitungan dan dapat dipakai sebagai acuan dalam pengambilan keputusan perencaanaan produksi.

Adapun saran yang dapat diberikan penulis pada penelitian ini adalah agar bisa dibuat system berbasis web sehingga semua orang bisa menggunakan.

\section{DAFTAR PUSTAKA}

Andi, Mahir Dalam 7 Hari Microsoft Access 2003, Madcoms Madiun, Yogyakarta, 2005. 
Bambang Yuwono, Bahan Kuliah Riset Operasional, Fakultas Teknologi Industri Universitas Pembangunan Nasional, Yogyakarta 2007.

Hotniar Siringoringo, Seri Teknik Riset Operasional Pemrograman Linear, Graha Ilmu, Yogyakarta, 2005.

Inge Martina, 36 Jam Belajar Komputer Pemrograman Visual Borland Delphi 7, ElexMedia Komputindo, Jakarta, 2004.

Johannes Supranto, Riset Operasi Untuk Pengambilan Keputusan, Universitas Indonesia, Jakarta, 1988.

Kuswara A., 2006. Pereancanaan Jumlah Produksi Optimal Dalam Mengoptimalkan Keuntungan Dengan Pendekatan Pemrograman Linier Berdasarkan Metode Simpleks Pada Pembuatan Teh Merk Sendiri (Studi Kasus di Industri Hilir The PT. PN VIII Bandung). Universitas Komputer Indonesia, Bandung
Made Pande Galih Darmarani, Program Linear Metode Simpleks, Fakultas MIPA Universitas Udayana, Bali, 2008.

Muhiddin Sirat, Metode Simpleks, Fakultas Ekonomi Universitas Lampung, Lampung, 2007.

Sipayung R.M.A., 2010. Optimisasi Kapasitas Produksi Menggunakan Metode Simpleks Untuk Memaksimalkan Laba Pada PT. Gold Coin Indonesia Medan- Mill, Universitas Sumatera Utara, Medan

Trihartoyo, S., 2005. Optimisasi Kapasitas Produksi Dengan Model Linier Programing Untuk Memaksimalkan Laba Pada PT. Mirasa Food Industri, Universitas Bina Nusantara, Jakarta

Uus Musalini,2004. Membuat Aplikasi Super Cantik dan Full Animasi dengan Delphi, ElexMedia Komputindo, Jakarta.

Yuniar Supardi, 2004.Borland Delphi Dalam Praktek, Datakom Lintas Buana, Jakarta. 